\title{
ANÁLISE DO FILME "POR LUGARES INCRÍVEIS": UM OLHAR PSICOSSOCIAL DA IDEAÇÃO SUICIDA ${ }^{1}$
}

\author{
ANALYSIS OF THE FILM "ALL THE BRIGHT PLACES": \\ A PSYCHOSOCIAL VIEW OF THE SUICIDE IDEATION
}

\section{Bibiana Massem Homercher ${ }^{2}$, Juliana Motta Magrini ${ }^{3}$ e Félix Miguel Nascimento Guazina ${ }^{4}$}

\section{RESUMO}

Este artigo tem como objetivo analisar o filme "Por Lugares Incríveis" a partir de uma perspectiva psicológica e social, visando retratar cenários referentes à adolescência e ao suicídio. A metodologia utilizada é de caráter qualitativo e bibliográfico, a qual possibilita realizar a análise fílmica. Os resultados demonstram uma importante ligação dos aspectos dos personagens do filme com questões significativas relacionadas à dimensão psicanalítica, psicossocial e de saúde mental, sendo uma delas os sofrimentos psíquicos, principalmente associados à adolescência e ao comportamento suicida. Assim, verifica-se a importância de que os profissionais da saúde ofereçam um olhar mais atento para o sofrimento do adolescente, buscando identificar e prevenir práticas que podem levar ao suicídio.

Palavras-chave: Adolescência. Cinematografia. Saúde Mental. Suicídio.

\section{ABSTRACT}

This paper aims to analyze the film "All the bright places" from a psychological and social perspective, aiming to portray scenarios related to the tens ages (the adolescence) and to suicide. The methodology used is of qualitative and bibliographic character, which makes it possible to carry out the cinematographic analysis. The results demonstrate an important link between the aspects of the characters with significant issues related to the psychoanalytic, psychosocial and mental health dimension, one of which is the psychological suffering, mainly associated with adolescence and suicidal behavior. Thus, indicating the importance of health professionals offering a closer look at the adolescent's suffering, seeking to identify and prevent practices that can lead to suicide.

Keywords: Adolescence. Cinematography. Mental health. Suicide.

1 Trabalho de Residência Multiprofissional em Saúde

2 Autor, Psicóloga, Residente Multiprofissional em Saúde Mental - Universidade Franciscana (UFN). E-mail: bibianamh@ hotmail.com

3 Autor, Assistente Social, Residente Multiprofissional em Saúde Mental - Universidade Franciscana (UFN). E-mail: juuhmagrini@hotmail.com

4 Orientador, Psicólogo, Doutor em Psicologia Social, Coordenador do Programa de Residência Multiprofissional em Saúde Mental - Universidade Franciscana (UFN). E-mail: guazina@gmail.com 


\section{INTRODUÇÃO}

Os filmes suscitam em seus espectadores diversos sentidos e interpretações, possibilitando refletir sobre o tema tratado, as imagens apresentadas e as relações interpessoais. Nesse contexto, ficção e realidade, geralmente, são comparados. O cinema, então, é um recurso importante à produção e à circulação de conhecimento, pois pode servir de embasamento para construir e analisar outras questões, como, por exemplo, aspectos psicossociais (HUNT, MARLANT, RAWLE, 2013).

O filme "Por Lugares Incríveis" foi escolhido para ser analisado em uma disciplina de Pós-Graduação em Residência Multiprofissional em Saúde Mental, pois o enredo apresenta questões relacionadas ao suicídio e à adolescência, um assunto que apresenta certa complexidade, podendo ser melhor aprofundado. Assim, a pesquisa foi construída sob uma perspectiva psicológica e social, já que, através de um olhar interdisciplinar, surge um horizonte maior de interpretações.

A adolescência é considerada um período do desenvolvimento humano, situada entre a infância e a vida adulta, e seu sentido é recente, pois foi definido apenas no século XX. A adolescência advém de construções sociais e históricas, sendo marcada pelas mudanças fisiológicas elucidadas pela puberdade (COUTINHO, 2009). De acordo com o Estatuto da Criança e do Adolescente (ECA), o adolescente se circunscreve na idade de 12 a 18 anos, já para a Organização Mundial da Saúde (OMS), esse período é dos 10 aos 19 anos (WORLD HEALTH ORGANIZATION, 1986; BRASIL, 1990; EISENSTEIN, 2005).

Assim como o conceito de adolescência, o termo juventude também emerge a partir de construções culturais e sócio-históricas, entretanto, não são vocábulos sinônimos. A adolescência estaria próxima de uma lógica desenvolvimentista, diferente da juventude, que se aproximaria da experiência específica da juventude naquele período histórico, atravessada por aspectos específicos daquela cultura, naquele marco de tempo. Dessa forma, a adolescência estaria endereçada para um aspecto mais particular e individual do instante de adolescer de cada sujeito, já a juventude teria um atravessamento do coletivo (COIMBRA, BOCCO, NASCIMENTO, 2005; SOUZA, 2014).

Em função do período da adolescência apresentar uma fragilidade psíquica significativa, sobretudo a partir das mudanças físicas, sociais e psicológicas que reverbera, os adolescentes são mais inclinados a ações imediatas e impulsivas por ainda não estarem com a plena maturidade emocional. Assim sendo, encontram maiores desafios de lidar com circunstâncias que gerem estresse, entretanto, nesse viés, é necessário diferenciar tais fenômenos que são passageiros e que não indicam patologias, daqueles que são sinais de alerta e perigo, podendo evoluir para um risco de suicídio (BOTEGA, 2015).

O suicídio é um problema gravíssimo de saúde pública, estando entre as vinte causas que levam o indivíduo a óbito no mundo, com estatísticas mais altas daquelas acarretadas pelo câncer de mama, guerra e malária, por exemplo. Cerca de 800.000 pessoas falecem em decorrência do suicídio 
por ano. O suicídio é a terceira causa principal entre indivíduos na faixa etária de 15 a 19 anos de ambos os sexos, sendo apontada como a segunda causa preponderante entre meninas de 15 a 19 anos (que posteriormente presenciaram condições de maternidade) e entre meninos nessa mesma faixa etária (após lesões aderidas de violências externas e acidentes do trânsito) (WORLD HEALTH ORGANIZATION, 2019).

O luto é um afeto, um sentimento normal que se expressa diante da perda de alguém ou de algo que seja precioso para o sujeito, sendo algo que acontece em algum instante da vida, sendo um processo fundamental para elaboração da perda de alguém ou de algo que era substancial para o indivíduo (FREUD, [1915] 2010; EDLER, 2018). O luto pode tornar-se patológico dependendo da sua durabilidade de tempo e do grau dos sintomas. Apesar disso, para além da visão delimitada por uma patologia, é importante oferecer um olhar subjetivo para o indivíduo que sofre a perda, pois o luto se trata de uma situação existencial onde o sujeito é colocado em relação àquela pessoa a qual perdeu (MICHEL; FREITAS, 2019). Pesquisas mostram que vivenciar perdas recentes pode ser considerado um fator de risco para o comportamento suicida (ORGANIZAÇÃO MUNDIAL DA SAÚDE, 2018).

Nesse contexto, refletir sobre o suicídio a partir do enredo de "Por Lugares Incríveis" pode ser um movimento interessante de pesquisa, já que o filme é apresentado em torno de um relacionamento adolescente no qual um dos personagens comete suicídio. Em termos gerais, aproximando ficção e realidade, pode-se tomar a adolescência como um período da vida que necessita de maior atenção por parte da família e dos profissionais da saúde, principalmente nas questões relacionadas à saúde mental, já que, segundo pesquisas recentes, o adolescente apresenta uma estimativa considerável na prevalência de transtornos mentais (FLEITLICH; GOODMAN, 2002). Assim sendo, nesse momento da vida, o risco do comportamento suicida é alto, fato que pode ser decorrente do próprio transtorno que o indivíduo apresenta ao estar formando sua personalidade (ESTELLITA-LINS; OLIVEIRA; COUTINHO, 2006; CICOGNA, HILLESHEIM, HALLAL, 2019).

O filme em questão traz dois adolescentes que estão em risco psíquico e buscam enfrentar seus sofrimentos mentais, sem possuírem qualquer suporte familiar ou profissional. Então, são dois indivíduos que não possuem amparo e rede apoio e buscam conforto e ajuda neles mesmos. Desse modo, com o olhar psicossocial, foi possível não só compreender e propor outros caminhos para que a alternativa do personagem não fosse o suicídio, mas também mostrar como o transtorno mental não acompanhado por um profissional pode ser (ou foi) o desencadeante nessa decisão.

Uma análise fílmica de "Por Lugares Incríveis" mostrou-se fundamental para problematizar o transtorno mental, a saúde mental, o suicídio, a adolescência e a importância de um trabalho interdisciplinar. O filme permite questionar o que levou aquele adolescente a cometer suicídio, se foi algo relacionado a alguma patologia, se foi falta de suporte familiar e/ou auxílio profissional, ou todos esses fatores conectados. Ao longo do artigo, tais questões são discutidas pelas autoras. 


\section{METODOLOGIA}

Esta pesquisa é oriunda de uma disciplina de Pós-Graduação em Residência Multiprofissional em Saúde Mental vinculada a uma universidade no interior do Estado do Rio Grande do Sul. Este estudo é de cunho qualitativo com caráter bibliográfico de análise de arte fílmica, consistindo em analisar de forma psicológica e social o filme "Por Lugares Incríveis" (MINAYO; COSTA, 2018).

A partir da investigação do filme, consideraram-se as seguintes bases bibliográficas para a coleta de dados: Biblioteca Eletrônica Científica Online (SCIELO); Periódicos Eletrônicos de Psicologia (PePSIC) - especificamente publicações no período de 2002 a 2020 -; livros (de autores clássicos e contemporâneos), revistas, legislações, estatutos nacionais e internacionais. As palavras-chaves selecionados para a pesquisa são as seguintes: adolescência; cinematografia; saúde mental; suicídio.

Segundo Minayo (1996), a pesquisa qualitativa é aquela que se aplica a saberes referentes à história, relações, percepções, ideias e opiniões, produções visualizadas e interpretadas pelos seres humanos sobre o modo como vivem as circunstâncias, os fatos que os rodeiam, como desenvolvem seus artefatos e a si mesmos, como sentem e pensam. Com isso, esta proposta consiste em aprofundar o enredo cinematográfico associando-o a fenômenos psíquicos e sociais.

Para Peter Loizos (2008), a análise fílmica está relacionada ao uso do recurso visual como documento de pesquisa. O autor observa que uma imagem, com ou sem som, já consegue efetuar impacto, e sua utilização em um estudo tem lugar como um dado primário que elucida fenômenos teóricos, abstratos e sociais a serem analisados e compreendidos. O recurso cinematográfico, filme ou vídeo - tomados na mesma proporção pelo autor -, pode contribuir de forma substancial para compreender aspectos da realidade humana.

Assim sendo, foi realizada uma leitura atenta e profunda dos diálogos e narrativas do filme. Da mesma forma, foram organizados de modo cronológico os acontecimentos do enredo, o desenvolvimento dos protagonistas, as situações, as crises, os começos e os fins, além, também, dos aspectos não cronológicos (as explicações, os motivos que estão subentendidos e que fundamentam tal narrativa). Esses movimentos interpretativos explicitam que entender uma história é não só observá-la para além dos acontecimentos descritos, mas também considerar a teia de sentidos que estrutura a narrativa em sua integralidade (BAUER; JOVCHELOVITCH, 2008).

Dessa forma, ao longo do artigo, primeiramente é apresentando o enredo do filme e, posteriormente, nos resultados e discussões, é contextualizado o processo da adolescência correlacionado aos protagonistas do filme. As histórias dos personagens, manifestadas na trama cinematográfica, são empregadas como um dispositivo analisador. Propõe-se uma análise psicossocial da trama de forma integrada, refletindo e discutindo sobre o suicídio, essencialmente, no período da adolescência.

O filme All The Bright Places (em português, “Por Lugares Incríveis”), lançado, em 2020, pela plataforma Netflix, é considerado um drama adolescente dirigido por Brett Haley. Aborda a história 
de Violet e Theodore que, a partir de um encontro peculiar, dão às suas vidas outra direção. O filme é baseado no romance da autora norte americana Jennifer Niven - filme e livro têm o mesmo título -, fundamentado em fatos reais da vida da escritora (NIVEN, 2015).

Os caminhos dos dois protagonistas se cruzam quando, por volta das cinco horas da manhã, devido a uma forte ansiedade, Theodore sai para correr, enxerga Violet em cima de uma ponte (demonstrando interesse em pular) e, então, a impede de cometer o ato. Eles já se conheciam, pois estudavam na mesma escola. É apresentado ao telespectador que Violet perdeu a irmã mais velha em um acidente de carro e, mesmo depois de um ano do ocorrido, ainda estava expressando muito sofrimento, sentia-se culpada pelo ocorrido, ela tentaria o suicídio no dia em que a irmã estaria completando mais um ano de vida.

Theodore tem problemas comportamentais e emocionais em virtude da relação conturbada com seu pai (que o violentava) na infância e a distância de sua mãe. O contato familiar mais próximo (único) que Theodore tem com a família é com sua irmã mais velha, responsável por ele. Na escola, Theodore conversava com o conselheiro escolar em virtude de seus comportamentos agressivos, entretanto, não tinha acompanhamento de nenhum profissional especializado.

Theodore começa uma aproximação com Violet e os dois iniciam um relacionamento amoroso a partir do momento em que ele a convida para fazer um trabalho de aula - que trazia a proposta de apresentar lugares considerados marcantes de sua cidade. Theodore tem poucos amigos e sofre bullying diariamente no ambiente escolar, já Violet, depois do falecimento da irmã, afasta-se dos amigos.

Em alguns momentos, Theodore costuma ficar embaixo da água na banheira mais tempo do que o "normal" e um dia quando vai com Violet para o rio, isso acontece e ela se desespera, mas logo ele reaparece. Violet e Theodore começam a ter conflitos no namoro, Theodore entra em uma crise, manifestando, novamente, comportamentos violentos, chegando a agredir um rapaz que comete bullying com ele na escola.

A relação do casal termina de modo intenso e conflituoso, o que o leva a cometer suicídio no rio, dias depois, entrando em óbito por afogamento. A partir do enredo dessa obra cinematográfica, este artigo se propõe a investigar, sob o olhar psicológico e social, os personagens que compõem a história e o cenário que constitui a trama do filme.

\section{RESULTADOS E DISCUSSÕES}

\section{Adolescência: Definições e Atravessamentos Psicanalíticos}

O vocábulo adolescência advém do latim adulescents ou adolescens, sendo o particípio do verbo adolescere, que tem como sentido crescer (PECHON, [1964] 1993; COUTINHO, 2009; DOURADO et al., 2020). Sendo atravessada pelas alterações corporais elucidadas pela puberdade, 
que acontecem ao final da infância, a adolescência seria um período de transição, marcado por aspectos psicológicos e sociais, situando-se no período do desenvolvimento humano, aproximadamente a segunda década da vida (COUTINHO, 2009; DOURADO et al., 2020).

Para Jerusalinsky (2004), a adolescência é definida de forma reducionista quando apenas é relacionada a uma coordenada temporal, ou seja, quando não consegue abranger a complexidade de questões que a constitui. Uma maneira de contrapor o reducionismo talvez seja partir da ideia de que a adolescência é um estado de espírito, independentemente da idade, marcado por uma turbulência e uma instabilidade que podem ser visualizadas em sujeitos que se encontram no processo de adolescer. Apesar disso, a palavra adolescência também mostra o "adoecer", pois fala de um sofrimento que é próprio da perda de proteção, que caracterizava a fase anterior, a infância.

Considerando o desenvolvimento da criança até atingir a adolescência, sabe-se que o bebê humano se difere dos outros animais por receber absolutamente tudo adequado para ele (até mesmo o lugar onde vive, o mundo onde se situa), diferentemente das outras espécies que, quando nascem, encontram-se num mundo já produzido, dado, pronto. Os leões, as zebras, os elefantes não moldam o mundo para seus filhotes, não o fabricam, eles nascem na floresta e a floresta está feita (JERUSALINSKY, 2004).

O humano produz um mundo, entretanto, no que diz respeito ao corpo, não consegue mudar o modo como ele já vem feito. Ao longo desse processo, o corpo pressiona, cobra um alto preço de sua presença na ordem simbólica. Por isso, é muito difícil para os adolescentes esquecerem do corpo, pois é um lugar que está em um plano simbólico que lhe é adquirido, esse corpo começa a sofrer mudanças na puberdade, demandas urgentes de muita importância, e isso perturba, pois modifica a posição desse corpo em relação ao conjunto social (JERUSALINSKY, 2004).

O adolescente é um ser que sofre, que transtorna a família e se sente asfixiado por ela, é aquele que observa a eclosão do próprio pensamento e o nascimento de algo novo, uma nova força. A adolescência é uma das fases mais substanciais da existência humana, pois, por um lado, o corpo alcança a morfologia adulta e é capaz de procriar, por outro lado, o ser é atingido por grandes questões - existenciais -, ele conquista o espaço da intelectualidade, conquista um lugar afetivo, inclina-se a descobertas de novos interesses socioculturais, e, finalmente, sai do círculo familiar e encontra seu espaço social, o universo dos outros humanos com toda a gama de diversidades. É nesse estágio de desenvolvimento e maturação que o indivíduo percebe o quanto o outro é afetivo, biológico e socialmente vital, o quanto necessita do outro para ser ele mesmo (NASIO, 2011).

A porta que se abre para a realidade dos adultos, ao mesmo tempo desejada e temida pelos jovens, significa para o adolescente a perda definitiva e inevitável da condição infantil. É um momento essencial na vida do homem, pois é o fim de um processo de desprendimento que iniciou com o nascimento. As transformações psíquicas que ocorrem nesse período, ligadas às mudanças fisiológicas, encaminham uma nova relação com os pais e com o mundo. Isso só é possível a partir 
da elaboração, lenta e dolorosa, do luto do corpo da criança, pela identidade infantil e seu relacionamento com os pais (ABERASTURY; KNOBEL, 1981).

O adolescente deve, no mesmo instante, perder, conservar e conquistar: perder o seu corpo infantil e o ambiente familiar onde cresceu; conservar as cargas afetivas que sentiu e vivenciou, percebeu e desejou desde do nascimento, e, principalmente, sua inocência de criança; e conquistar, finalmente, a vida adulta. O luto é um tempo substancial para aceitar conviver com a ausência definitiva daquele que amamos e que acabamos de perder. O luto infantil é um movimento de distanciamento que abarca, em muitos momentos, um sofrimento por desprender-se dos aspectos infantis, o adolescente retorna-os sucessivamente e, a cada retorno, há um novo micronascimento, isso leva o adolescente, aos poucos, ao amadurecimento (NASIO, 2011).

Tratar o "crescer" como um problema é substancialmente um tema contemporâneo. No conto de Peter Pan e Wendy, por exemplo, há uma analogia sobre a problemática da criança: Peter Pan, o menino que se recusa a crescer e que passa a vida a ter aventuras mágicas na Terra do Nunca, frequentemente, invade a casa de outros humanos e a casa da Senhora Darling para ouvir histórias e poder contá-las, posteriormente, aos meninos perdidos na Terra do Nunca. A grande novidade da história de Peter Pan é analisar o crescimento como algo que depende do desejo da criança para que ocorra (CORSO; LICHTENSTEIN, 2006).

As demandas e exigências sociais, tais como estudar, trabalhar, namorar, casar, ter filhos, assim como a forçosa imposição da mudança corporal que compele a maturação física, não teriam tanta relevância diante do desejo da criança, pois abandonar a infância implica a perda de identidade. É como se houvesse um deslocamento para uma terra estrangeira sem passaporte de volta, pois essa nova terra faz com que o indivíduo seja obrigado a esquecer tudo sobre a língua, os costumes, cheiros e sabores da terra natal, de certa forma, acessar a vida adulta gera uma "amnésia" da infância (CORSO; LICHTENSTEIN, 2006).

\section{O processo de construção da adolescência: um olhar psicanalítico para os personagens Violet e Theodore do filme "Por Lugares Incríveis"}

O filme "Por Lugares Incríveis" traz as diversas realidades que os adolescentes vivenciam a todo o momento. A partir do enredo, pode-se refletir que abstrair a adolescência do "continuum" que é o processo evolutivo e analisá-la apenas como uma etapa de preparação para o mundo adulto, para a maturidade, é um "adultomorfismo" que é preciso sobrepujar, pois induz prejuízos no olhar para a adolescência - ao invés de ser um olhar amplo, torna-se restrito, pequeno e reducionista. Ademais, ocorrem muitas flutuações de humor e ânimo no episódio da adolescência, principalmente a depressão e o luto, que, dependendo do caso, podem levar ao suicídio (ABERASTURY; KNOBEL, 1981). 
Nota-se que Violet Markey, uma das protagonistas do filme, tem 16 ou 17 anos, cor branca, reside com os pais, sofre uma perda significativa em sua vida: sua irmã falece, de maneira inesperada, em um acidente de carro na cidade onde mora. Após um ano do acidente, Violet ainda manifesta muito sofrimento pela perda, ela não pode estar em contato com nada que recorde a irmã, como entrar em carros, por exemplo, pois isso incita uma crise; ela, que se sente culpada pelo acidente, também se afastou dos amigos para não vivenciar o afeto. A personagem se encontra em um processo de luto pela perda da irmã. Freud ([1915] 2010) assevera que o luto é uma reação que o indivíduo apresenta à perda de uma pessoa amada, mas também pode ser uma forma de abstração, como um lugar que era ocupado, um ideal, entre outros.

Apesar de o luto ser um processo natural quando acontece a perda de um ente querido, percebe-se que o advento da morte da irmã foi traumático para Violet. Por ter sido de modo violento (Violet estava presente no acidente de carro com a irmã), a dimensão do trauma é desestruturante. A situação traumática, quando não é elaborada e simbolizada, pode deixar marcas psíquicas infindáveis no sujeito (SAVIETTO, 2010).

Pode-se visualizar que a personagem, mesmo após um ano, ainda apresenta resquícios significativos de sofrimento pelo falecimento da irmã - que foi de modo inesperado, brutal e traumático -, ela tem dificuldades para entrar em carros, evita abordar sobre o assunto e tem o afeto restrito, deixando de se aproximar de seus antigos amigos, além da quase tentativa de suicídio em virtude do sofrimento que ainda sente após o acidente. Sua aproximação com Theodore faz com que esses sintomas, aos poucos, vão sendo controlados, encorajando-a, inclusive, a conversar com seu pai sobre o ocorrido.

O processo de vivência do luto é relativo à atividade psíquica de cada sujeito, está associado à apropriação íntima da vivência da perda. Para que aconteça, muitas funções estão interligadas, tais como as capacidades cognitivas e emocionais para dar algum sentido àquela perda, suportar a irreversibilidade da morte e lidar com sensações ambivalentes, angustiantes e de culpa, sendo um desafio para uma possível reparação psíquica (MANO, 2016).

Dessa forma, é a incapacidade de representação da morte que leva Violet à tentativa de suicídio no dia em que a irmã completaria mais um ano de vida. É a chegada de Theodore que a impede de cometer o ato, sendo ele uma ponte para a possibilidade de simbolizar o luto, propiciando um novo caminho para a dor - que não seja a morte.

No caso de Theodore Finch, o sofrimento psíquico é diferente do cenário de Violet. Ele tem entre 16 e 17 anos, sexo masculino, cor preta, mora com a irmã e a mãe (seus pais são divorciados). Theodore sofre bullying na escola devido ao seu comportamento mais agressivo em relação a alguns colegas. Ser negro pode ser um marcador social importante para o seu sofrimento dentro do ambiente colegial, sobretudo para o desenvolvimento psicológico e social das crianças e adolescentes negros, que são, previamente, excluídos pela cor (FANON, [1952] 2008). 
A mãe de Theodore é bastante ausente, nem mesmo aparece no filme, é sua irmã mais velha uem fica encarregada da responsabilidade tanto financeira quanto afetiva da sua criação. O adolescente tem poucos amigos, ele costuma sair para correr quando se sente ansioso e também costuma mergulhar-se dentro da água na banheira como um modo de aliviar sua tensão. Há uma identificação quase que imediata com a situação de Violet - que iria cometer suicídio - e os dois, aos poucos, pela insistência de Theodore, se aproximam e têm um relacionamento amoroso.

Descobre-se que Theodore foi violentado pelo pai na infância, apresentando uma cicatriz no abdômen de um possível esfaqueamento. Na infância e na adolescência, a falta de afeto dos cuidadores pode gerar perdas e traumas significativos no desenvolvimento psíquico do sujeito (PROCHET, 2016). O retrato do desamparo tem ligação com a violência traumática, que é trágica, fazendo com que o sujeito fique imerso nessa sensação (MANO, 2016).

A passagem da adolescência é repleta de uma fragilidade narcísica e seu processo pode ser considerado como uma violência interna, pulsional. A adolescência manifesta circunstâncias que foram significativas da infância, desse modo, se o sujeito teve falhas narcísicas nesse período, isso será possivelmente ressurgido na vivência psíquica do adolescente, quando pode desencadear patologias. Por isso a importância de que um suporte parental na transição narcísica seja efetivado na adolescência (SAVIETTO, 2010).

Por mais que o relacionamento entre Violet e Theodore desperte sentimentos constitutivos nos dois, Theodore começa a manifestar conflitos para ambos ao desaparecer inesperadamente - torna-se recorrentes suas saídas para se isolar. Aos poucos, isso começa a aparecer no filme, os atendimentos com o conselheiro da escola não são mais suficientes e ele vai em um encontro grupal, pois tem dificuldades de controlar a raiva. Theodore utiliza bloquinhos para colar na parede sensações, sentimentos, acontecimentos que fazem com que dê sentido à sua vida, porém, com o passar do filme, ele destrói esses bloquinhos em um instante de crise.

Theodore apresenta um sofrimento psíquico pela falta de suporte emocional da família - por mais que a irmã esteja presente, e suas tentativas de simbolizar a dor através dos bloquinhos, dos encontros grupais e também com o relacionamento amoroso com Violet -, a falta do cuidado materno e paterno em sua vida refletem em sua adolescência, despertando sentimentos de solidão, raiva e medo, oriundos da excessiva sensação de angústia que impossibilitam a via simbólica para sair desse naufrágio de desamparo (MANO, 2016). Por isso, ao final do filme, Theodore discute com Violet, pede que ela não o procure mais e, por fim, se suicida no rio onde costumava levar Violet.

\section{Análise psicossocial do filme "Por Lugares Incríveis"}

O que seriam esses lugares incríveis que o filme aborda? O relacionamento de Violet e Theodore desenvolve-se nesses locais, em uma cidade com poucos pontos turísticos: tudo começou a partir 
de um trabalho da escola. É possível analisar que esses lugares estão além da ideia de um cenário externo, estabelecendo uma relação com a procura de dois sujeitos, que se encontram em sofrimento psíquico, por um sentido para o viver. Visitar cenários novos e desconhecidos da cidade onde vivem também é um modo de encontrar novas vias de lidar com a dor, com o luto, com o abandono e o desamparo, e não se sentirem completamente sozinhos em meio ao sofrimento.

O filme não é apenas um romance adolescente, ele também aborda questões da saúde mental na adolescência e como essa fase apresenta uma fragilidade singular. Além da mudança física e mental, os adolescentes, protagonistas do filme, passaram por circunstâncias delicadas em suas vidas, ao ponto de um deles cometer suicídio. A adolescência em si tem um "compêndio de transmutações" (ABERASTURY; KNOBEL, 1981) e isso exige cuidado e um olhar mais atento para o desenvolvimento do adolescente.

O suicídio está entre as dez principais formas de morte no mundo, sendo considerada uma das três maiores causas de óbito na faixa etária de quinze a trinta e cinco anos (ESTELLITA-LINS; OLIVEIRA; COUTINHO, 2006). Na adolescência, o suicídio é considerado a terceira principal causa de morte (SOUZA et al., 2010). Os sofrimentos psíquicos (personalidade, humor, substâncias psicoativas, entre outros) são considerados fatores de risco para o suicídio, além das condições sociodemográficas (o sexo masculino é o que mais comete suicídio), psicológicas (perdas recentes, perdas de figuras significativas da infância) e clínicas incapacitantes (por exemplo: doenças orgânicas incapacitantes) (BRASIL, 2006).

Nota-se que Violet e Theodore encontravam-se em situações de risco, a perda da irmã quase levou Violet à tentativa de suicídio, e Theodore, em virtude de suas questões psicológicas, cometeu o ato. Dessa forma, as questões relacionadas ao suicídio, por mais complexas que sejam, necessitam desse olhar imediato, sem julgamentos, de um acolhimento, de uma escuta, de uma possibilidade de encontro afetivo com o outro (BRASIL, 2006), o que, temporariamente, aconteceu através do laço de amor entre os personagens e dos lugares incríveis que descobriram dentro e fora de si mesmos, mas que não evitou que um dos dois viesse a se suicidar. Ambos precisavam de um amparo maior, no que tange à saúde mental.

Conforme uma análise social e psicossocial, percebeu-se que os dois adolescentes lutam contra seus sofrimentos psíquicos, porém Theodore enfrenta esse momento de uma forma mais solitária porque seus pais, como mostra o filme, não fazem parte do seu dia a dia. Desse modo, a saúde mental de Theodore é afetada, pois um adolescente necessita de um suporte familiar.

O apoio familiar tanto quanto o de um profissional, como nesse caso o de um Assistente Social, é indispensável e primordial. A família auxilia no cuidado, na questão financeira, dá apoio emocional e contribui para que haja uma melhora na saúde mental. Conforme ressaltam Rosa e Melo (2009), as unidades familiares são as principais mediações entre a sociedade e as pessoas com sofrimento psíquico. 
É importante que os profissionais da área de saúde mental, de modo especial os assistentes sociais em sua intervenção junto a família, atentem para esta realidade, para que propiciem aquela possibilidade de superar as dificuldades vividas [...] através da oferta de serviços de atenção psicossocial diário, oferecendo-lhe o apoio necessário dos serviços [...] (PEREIRA, 2000, p. 254).

Portanto, o auxílio de um Assistente Social seria fundamental ao adolescente Theodore, uma vez que ele não tem contato com o pai e sua mãe não está fazendo parte do seu dia a dia, é a irmã a única pessoa quem se responsabiliza por ele. Desse modo, o Assistente Social contribuiria possibilitando que a mãe desse adolescente fosse assistida através de um suporte social e assistencial, buscando maneiras de ela estabelecer mais contato com os filhos, seja através de um auxílio financeiro, seja compreendendo se essa mãe está vivenciando um processo de adoecimento decorrente de um companheiro violento. $\mathrm{O}$ alvo predominante do exercício profissional do Assistente Social é o trabalhador e a sua família, em todos os espaços ocupacionais (IAMAMOTO; CARVALHO, 1983).

Outra questão que merece atenção é o bullying que o adolescente sofre no ambiente escolar. Tal situação realça um possível desfecho diferente para a história se a escola possuísse um profissional como o Assistente Social para buscar alternativas de mediação dos conflitos interpessoais. Todos os movimentos que proporcionam a conscientização da importância do respeito diante de uma pessoa que está em sofrimento e ações que favoreçam a prática da cidadania e da inclusão social podem intervir de maneira positiva nas demandas sociais existentes (NUNES; SILVA, 2014).

Pensando na saúde como um todo, o suicídio está em uma dimensão complexa, pois é um campo repleto de desafios. A morte, através do ato de suicidar-se, reverbera repercussões no social e na cultura. Na atuação do Psicólogo, o olhar não deve ser apenas voltado para o paciente, mas também para a família e a equipe de saúde, pois o profissional da psicologia precisa lidar com os tabus e fenômenos morais envolvidos entorno do suicídio. O Psicólogo necessita estar atento ao fato de que, antes de tudo que aglomera o suicídio (em termos estatísticos, culturais, sociais e históricos), o que está presente, essencialmente, é um sujeito em extremo sofrimento (CONSELHO FEDERAL DE PSICOLOGIA, 2013).

O modo como é feita a abordagem da pessoa que demonstra ideação suicida ou já manifestou tentativas de suicídio é essencial para o acolhimento desse indivíduo. Uma escuta atenta, sem julgamentos, com demonstração de empatia e um posicionamento ético são essenciais no trabalho do Psicólogo, independente do campo de atuação. É importante criar um ambiente acolhedor, ouvir atentamente, permitir um espaço em que a pessoa possa manifestar o que sente (BRASIL, 2006).

Percebe-se que o manejo que o Psicólogo tem nessas circunstâncias requer disposição, respeito, tolerância à frustração e atuação interdisciplinar. O Psicólogo precisa compreender a falta de sentido do outro e procurar não ocupar um lugar de onipotência, tampouco de impotência, pois apesar do trabalho de prevenção, não há garantias de que o suicídio não poderá vir a acontecer (FUKUMITSU, 2014). 
Apesar dos riscos, a prevenção é uma das principais alternativas nos casos de ideação e tentativa de suicídio, pois, de modo global, ela é possível. O trabalho com a prevenção do suicídio não inclui apenas o Psicólogo, mas também diversos profissionais da saúde, que precisam estar instrumentalizados para atender esses casos, auxiliando para que esses indivíduos encontrem novas vias de invenção para lidar com o sofrimento, que não sejam apenas a morte (CONSELHO FEDERAL DE PSICOLOGIA, 2013).

\section{CONSIDERAÇÕES FINAIS}

A cinematografia tem suas interlocuções com a realidade, com circunstâncias factuais que estão presentes no cotidiano e, principalmente, com os profissionais que atuam diretamente com adolescentes. Ao longo desta pesquisa, foram reiteradas as visões do Assistente Social e do Psicólogo, entretanto, muitos outros profissionais da saúde e da área da educação auxiliam nas questões relacionadas ao desenvolvimento humano, que são essenciais para identificar o sofrimento dos jovens nessa faixa etária.

O filme "Por Lugares Incríveis" aborda um contexto delicado, o suicídio entre os jovens, situação que necessita de atenção da família, da comunidade, da escola e dos profissionais capacitados para o cuidado em promoção e prevenção da saúde dos adolescentes. A falta de olhar para o sofrimento adolescente pode ter consequências sérias na vida do sujeito, inclusive, como no caso do filme, em que acontece um suicídio.

O suicídio é uma questão complexa, considerado significativo no âmbito da saúde mental, principalmente quando é pensado no período da adolescência - quando os sujeitos se encontram em um momento de fragilidade narcísica e de transição para a vida adulta, que, por si só, já é um processo doloroso. O filme, então, poder ser tomado para além da dimensão ficcional, pois é um instrumento disparador de reflexões que estão cotidianamente presentes na realidade social, cultural e psicológica.

Dessa forma, o excesso de sensações ambivalentes, angústias e experiências que reverberam na adolescência precisa ser escutado, visualizado e compreendido. Muitas vezes, os adolescentes demonstram seu sofrimento no silêncio, na raiva, na agressividade, nas fugas, como ocorre com os protagonistas Theodore e Violet, e é preciso estar atento a esses sinais. O que o filme aborda é, essencialmente, esse sofrimento psíquico que muitos adolescentes vivenciam diariamente e que precisam de cuidado, atenção e amparo, principalmente por parte das pessoas mais próximas, que são os familiares.

Portanto, é importante possibilitar esses "lugares incríveis" também dentro do âmbito da família e da saúde. É preciso mostrar ao adolescente lugares reais ou imaginários em que ele possa sentir-se acolhido em relação ao seu sofrimento. É fundamental construir estratégias para lidar com a dor. Esses "lugares incríveis" podem ser vias para a vida, para encontrar laços afetivos em que o sujeito adolescente não se sinta solitário perante o seu sofrimento. 


\section{REFERÊNCIAS}

ABERASTURY, A.; KNOBEL, M. Adolescência Normal: Um Enfoque Psicanalítico. Porto Alegre: Artes Médicas, 1981.

ALL THE Bright Places. Internet Movie Database. Direção de Brett Haley. Roteiro de Liz Hannah. Estados Unidos, 2020. Disponível em: https://www.imdb.com/title/tt3907584/. Acesso em: 16 maio 2020.

BAUER, M. W.; JOVCHELOVITCH, S. Entrevista Narrativa. In: BAUER, M. W.; GASKELL, G. Pesquisa Qualitativa com Texto, Imagem e Som: Um Manual Prático. Petrópolis, Rio de Janeiro: Editora Vozes, 2008.

BOtEGA, N. J. Crise Suicida: Avaliação e Manejo. Porto Alegre: Artmed, 2015.

BRASIL. Ministério da Justiça. Lei 8.069, de 13 de julho de 1990. Estatuto da Criança e do Adolescente. Brasília, Distrito Federal, 1990.

BRASIL. Ministério da Saúde. Prevenção do Suicídio: Manual dirigido a profissionais das equipes de saúde mental. Brasil, Distrito Federal, outubro de 2006.

CICOGNA, J. I. R.; HILlESHEIM, D.; HALLAL, A. L. L. C. Mortalidade por suicídio de adolescentes no Brasil: tendência temporal de crescimento entre 2000 e 2015. Jornal Brasileiro de Psiquiatria, v. 1, n. 68, Rio de Janeiro, jan./mar. 2019. Disponível em: https://bit.ly/3156tLk. Acesso em: 22 out. 2020.

COIMBRA, C.; BOCCO, F.; NASCIMENTO, M. L. Subvertendo o conceito de adolescência. Arquivos Brasileiros de Psicologia, Rio de Janeiro, v. 57, n. 1, p. 2-11, jun. 2005. Disponível em: https://bit.ly/ 3iUvBSg. Acesso em: 22 jun. 2021.

CONSELHO FEDERAL DE PSICOLOGIA. O suicídio e os desafios para a psicologia. Brasília, DF, dezembro, 2013.

CORSO, M.; LICHTENSTEIN, D. Fadas no Divã. Porto Alegre: Artmed, 2006.

COUTINHO, L. G. Adolescência e Errância: Destinos do Laço Social no Contemporâneo. Rio de Janeiro: Nau FAPERG, 2009. 
DOURADO, J. V. L. et al. Definições, Critérios e Indicadores da Adolescência. Revista de Enfermagem UFPE online, 2020. Disponível em: https://bit.ly/3iZXpEH. Acesso em: 23 jun. 2021.

EDLER, S. Luto e Melancolia: À Sombra do Espetáculo. 4. ed. Rio de Janeiro: Civilização Brasileira, 2018.

EISENSTEIN, E. Adolescência: definições, conceitos e critérios. Adolescência \& Saúde, v. 2, n. 2, junho 2005. Disponível em: https://bit.ly/3zS7VEL. Acesso em: 22 jun. 2021.

ESTELlitA-LinS, C;; OLIVEIRA, V. M.; COUTINHO, M. F. C. Acompanhamento terapêutico: intervenção sobre a depressão e o suicídio. Psychê, São Paulo, n. 18, p. 151-166, setembro, 2006. Disponível em: https://bit.ly/3fcmv2i. Acesso em: 16 maio 2020.

FANON, F. Pele Negra, Máscaras Brancas. Salvador: EDUFBA, [1952] 2008.

FLEITLICH, B. W.; GOODMAN, R. Implantação e implementação de serviços de saúde mental comunitários para crianças e adolescentes. Revista Brasileira de Psiquiatria, 2002. Disponível em: https://bit.ly/3ycY507. Acesso em: 22 out. 2020.

FREUD, S. Introdução ao Narcisismo, Ensaios de Metapsicologia e outros Textos (1914-1916). In: FREUD, S. Luto e Melancolia. São Paulo, Companhia das Letras, [1915] 2010.

FUKUMITSU, K. O. O psicoterapeuta diante do comportamento suicida. Psicologia USP, v. 25, n. 3, p. 270-275, 2014. Disponível em: https://bit.ly/317XQ2D. Acesso em: 16 maio 2020.

HUNT, R. E.; MARLAND, J.; RAWLE, S. A Linguagem do Cinema: Coleção Fundamentos de Cinema. Porto Alegre: Bookman, 2013.

IAMAMOTO, M.; CARVALHO, R. Relações sociais e serviço social no Brasil: esboço de uma interpretação histórico-metodológica. São Paulo: Cortez, 1983.

JERUSALINSKY, A. Adolescência e contemporaneidade. In: MELLO, A.; CASTRO, A. L. S.; GEIGER, M. (Org.). Conversando sobre adolescência e contemporaneidade. Porto Alegre: Editora Libretos, p. 54-65, 2004. 
LOIZOS, P. Vídeo, Filme e Fotografias como Documento de Pesquisa. In: BAUER, M. W.; GASKELL, G. Pesquisa Qualitativa com Texto, Imagem e Som: Um Manual Prático. Petrópolis, Rio de Janeiro: Editora Vozes, 2008.

MANO, B. O brincar impossível: luto e representação. In: CÍRCULO PSICANALÍTICO DO RIO DE JANEIRO / SOCIEDADE DE PSICANÁLISE DA CIDADE DO RIO DE JANEIRO. Trauma e luto na criança e no adolescente: uma visão psicanalítica. Psicanálise e Cinema, Rio de Janeiro: CPRJ/ SPCRJ, v. 4, n. 4, 2016. Disponível em: https://bit.ly/2V2pL9t. Acesso em: 22 out. 2020.

MICHEL, L. H. F.; FREITAS, J. L. A clínica do luto e seus critérios diagnósticos: possíveis contribuições de Tatossian. Psicologia USP, v. 30, 2019. Disponível em: https://bit.ly/3zRKw6m. Acesso em: 22 jun. 2021.

MINAYO, M. C. S. O desafio do conhecimento: pesquisa qualitativa em saúde. 4. ed., São Paulo; Rio de Janeiro: Hucitec; Abrasco, 1996.

MINAYO, M. C. S.; COSTA, A. P. Fundamentos Teóricos das Técnicas de Investigação Qualitativa. Revista Lusófona de Educação, n. 40, p. 139-153, 2018. Disponível em: https://bit.ly/2TGyZaH. Acesso em: 16 maio 2020.

NASIO, J. -D. Como agir com um adolescente difícil: um livro para pais e profissionais. Rio de Janeiro: Zahar, 2011.

NIVEN, J. Por Lugares Incríveis. Editora Seguinte, 2015.

NUNES, M.; SILVA, L. B. A Intervenção do Assistente Social nas Práticas do Bullying. Revista Interfaces: Saúde, Humanas e Tecnologia, v. 2, n. 5, 2014. Disponível em: https://bit.ly/3zNs279. Acesso em: 16 maio 2020.

ORGANIZAÇÃO MUNDIAL DA SAÚDE. Organização Pan-Americana da Saúde. Folha informativa - Suicídio. Brasília, 2018. Disponível em: https://bit.ly/37nee7r. Acesso em: 22 jun. 2021.

PECHON, D. (org.). Larousse - Dictionnaire Etymologique et Historique du Français. Paris, Larousse, [1964] 1990. 
PEREIRA, I. C. G. Do ajustamento à invenção da cidadania: Serviço social, saúde mental e intervenção na família no Brasil. In: VASCONCELOS, E. M. (Org). Saúde Mental e Serviço Social: o desafio da subjetividade e da interdisciplinaridade. São Paulo: Cortez, 2000. São Paulo: Cortez, 2000.

POR LUGARES Incríveis. Adoro Cinema. Direção de Brett Haley. Roteiro de Liz Hannah. Brasil, 2020. Disponível em: http://www.adorocinema.com/filmes/filme-239793/. Acesso em: 16 maio 2020.

PROCHET, N. Apresentação. In: CÍRCULO PSICANALÍTICO DO RIO DE JANEIRO / SOCIEDADE DE PSICANÁLISE DA CIDADE DO RIO DE JANEIRO. Trauma e luto na criança e no adolescente: uma visão psicanalítica. Psicanálise e Cinema, Rio de Janeiro: CPRJ/SPCRJ, v. 4, n. 4, 2016. Disponível em: https://bit.ly/3zQheFg. Acesso em: 22 out. 2020.

ROSA, L. C. S.; MELO, T. M. F. S. Inserções do assistente social em saúde mental: em foco o trabalho com as famílias. Serviço Social \& Saúde (UNICAMP), 2009. Disponível em: https://bit.ly/3ibtydr. Acesso em: 16 maio e 2020.

SAVIETTO, B. B. Adolescência: Ato e Atualidade. Curitiba, Juruá Editora, 2010.

SOUZA, L. B. Juventude e Adolescência sob o Olhar dos Jovens: Participantes do Projeto Jovem Aprendiz. Universidade Federal de Santa Catarina (UFSC): Trabalho de Conclusão de Curso, Florianópolis, 2014.

SOUZA, L. D. M. et al. Ideação suicida na adolescência: prevalência e fatores associados Jornal Brasileiro de Psiquiatria. n. 59, v. 4, p. 286-292, 2010. Disponível em: https://bit.ly/3BYkP6m. Acesso em: 16 maio 2020.

WORLD HEALTH ORGANIZATION. Suicide in the world. 2019. Disponível em: https://bit.ly/ 2WunHY9. Acesso em: 22 jun. 2021.

WORLD HEALTH ORGANIZATION. Young People's Health - a Challenge for Society. Report of a WHO Study Group on Young People and Health for All. Technical Report Series 731. Geneva: WHO, 1986. 